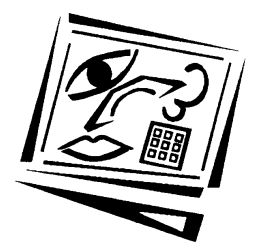

\title{
Do beginning teachers know how to participate and interact in online discussion? Outcomes from a Victorian case study
}

\author{
Kathy Jordan \\ RMIT University
}

\begin{abstract}
The use of online discussion has a long history in distance education and higher education generally, and has recently been proposed as a means of supporting beginning teachers as they face the challenge of being new to the profession. Often using text-based asynchronous programs, online discussion is advocated to enable teachers to interact with one another, and therefore remove teacher isolation and encourage reflective practice (Zhao \& Rop, 2001). This paper reports on a small scale study of 64 beginning teachers, who were asked to simulate online discussion, as a means of preparing them for later participation and interaction online. Transcripts were analysed using Henri's (1992) model of content analysis, revealing considerable one-way posts and few interactive posts. This study suggests that rather than being 'digital natives' (Prensky, 2001) these beginning teachers lacked the skills to participate and interact online.
\end{abstract}

\section{Introduction}

For some time now researchers here in Australia and overseas have explored the difficulties that beginning teachers face when they enter the profession, as well as the sometimes related issue of high rates of attrition (Darling-Hammond, 1990; De Wert Babinski \& Jones, 2003; Maxwell, Harrington \& Smith, 2010; Schuck, 2003). Herrington, Herrington, Kervin and Ferry (2006) suggest that in Australia around a quarter of beginning teachers leave within five years, and that in the United States, this figure is higher, with around a third leaving within their first five years of teaching. Many countries including Australia have induction programs (Schuck, 2003) or mentoring programs that aim to provide a supportive environment for beginning teachers. In Victoria for example, all beginning teachers (those in their first year of teaching) are assigned a mentor, under the Teacher Mentor Support Program (TMSP) (DEECD, 2011). Research tends to suggest however that despite good intentions, many of these programs are limited in their effectiveness (Schuck, 2003). There is consensus, here and elsewhere that more needs to be done to support beginning teachers.

Recently teacher networks have been proposed as a way to give beginning teachers more support. While teacher networks have been around for some time, they have mainly been used by pre-service teachers and practising teachers generally rather than beginning teacher specifically. Perhaps this lack of use relates to the fact that networks rely on agencies such as teacher professional subject associations, education departments or universities to support their development. Writing about teacher networks generally, Zhao and Rop (2001) suggest they have three main objectives: to 
exchange information such as resources, to transform practice by providing new knowledge or understanding, and to create or support reflective practice. Beginning teacher networks seem to more often focus on the third objective. Teacher networks, including beginning teacher networks, are often characterised by their use of an asynchronous technology, more often than not, text-based.

Beginning teacher networks, as teacher networks generally, use different methodologies to achieve their objectives. For example, they have different makeups. Some for example are completely online such as De Wert et al. (2003) while others involve face to face components such as Schuck (2003). Some only involve beginning teachers, for example Romano (2008), while others also involve experienced teachers (Schuck, 2003) and university staff (Maxwell, Harrington \& Smith, 2010). Some only involve beginning teachers from one school sector, as in Schuck's (2003) study of primary beginning teachers, while others involve beginning teachers from several sectors (De Wert et al., 2003; Romano, 2008). They can involve both small and large numbers of participants, as well as different operating periods - although they often don't go longer than a year and are powered by different technologies. Often the details of these technologies are not reported, in particular the possible effects from how the program was used, and under what conditions.

Zhao and Rop (2001) suggest that a number of factors are necessary for getting teachers to participate in online discussions. These include issues around technology, including having the technological skills as well as access to use online technologies, issues around having the motivation to want to participate, as well as issues around time, such as making time to participate as well as consideration of time needed to achieve project aims. Carr and Chambers (2006) in their more recent study similarly suggest these factors, as well as adding the lack of reflective practice culture in schools. Moore and Chae (2007) offer specific insights into why beginning teachers choose or don't choose to use online resources and communities established to support their needs, suggesting that for the most part, beginning teachers prefer to seek local professional and personal support from their colleagues.

\section{Online discussion}

The use of asynchronous technologies, also often referred to generically as online discussion, or computer mediated communication (CMC), has a long history in educational contexts with affordances often identified as solving perceived problems (Zhao \& Rop, 2001). For example in the 1980s, distance educators saw the asynchronous nature of online discussion as enabling students from geographically diverse locations to 'meet' online and therefore overcome the perceived lack of social presence associated with learning at a distance. From the 1990s, higher education institutions saw this asynchronicity as a way of giving students further opportunities to discuss course content and course issues, thereby overcoming the perceived barrier of needing to learn at a set location and time. Often, to do this higher education institutions invested heavily in building their own communication technologies. When it comes to why online discussion is advocated for teachers, Zhao and Rop (2001) argue that this practice continues: problems associated with teacher professional learning such as issues around teacher isolation and not having time to reflect on their practice, are identified and then particular affordances within online discussion are then assigned as solutions. As with distance education and higher education contexts generally, the asynchronous nature of online discussion is most commonly identified 
as providing solutions - that by being asynchronous teachers can participate at times that suit them, and can collaborate with other teachers outside their own immediate location. Zhao and Rop (2001) also argue that the text feature of asynchronous technologies is also identified as a beneficial affordance. In particular, that being written enables teachers to take time to express their views, thereby encouraging reflection.

Often, however, whether teachers know how to use online discussion technologies, and whether they receive training in how to use them is not reported or is lacking in details. In Romano's (2008) study, participants received technology professional learning, though what this involved is not specified. Likewise in Schuck's (2003) study, participants were given an introduction to the online tool but exactly how they were meant to use this tool is not reported. Often, training seems to relate to knowing how to use or operate the technology, and considerations such as how to use them (in what situations and under what conditions) and for what purposes (such as to engage with other participants) are overlooked. By not reporting on training, researchers can create the impression that online discussion is relatively simple, that it does not require specific training or skills, and that putting the technology into place is all that is needed. Attention to exploring whether teachers have the knowledge and skills to use them, both in a narrow functional sense, as well as a wider critical sense, is needed.

Zhao and Rop (2001) argue that while teacher network research often makes claims about their value, these are rarely evaluated, nor is a lot of evidence provided to substantiate them. In part they suggest that this is because much of the literature around teacher networks tends to take the form of descriptive accounts of practice, small case studies or project reports. Furthermore, they suggest a lot of assumptions are made about achieving goals. They highlight this by using the example of 'community' which they argue is often assumed to have been created, as a group of people were able to connect online. Teacher network research is also underpinned by techno-centric views, whereby particular affordances such as asynchronicity are portrayed as determining these effects. By consequence, the role of the teacher in relation to these effects is down played or side stepped. There is little consideration that teachers can shape these effects, nor the importance of social and cultural factors on practice. As well, little if any attention is given to the ways that online discussion once technically enabled can be sustained.

More recently, the use of online discussion by teachers as indeed technologies generally, are advocated on the grounds that beginning teachers as 'digital natives', are skilled users of technologies and are therefore equipped to take advantage of them (Gao, Wong, Choy \& Wu, 2010). Marc Prensky (2001) first coined this term to refer to the 'new' generation of students who having grown up with technologies in their lives were being influenced in the ways they think and learn, including having a liking for multi-tasking and thinking in multimodal ways. Prensky's view has been disputed on a number of grounds (Bennett, Maton \& Kervin, 2008; Kennedy, Judd, Churchward, Gray \& Krause 2008), yet despite these challenges, this notion of the digital native still has considerable traction.

\section{Participation and interaction in online discussion}

The two concepts of participation and interactivity are often common to online discussion research. While participation is considered important, it is interaction which is often seen as vital, as without it, researchers suggest that discussion can become a 
series of one way conversations, from oneself to oneself. Yet often both participation and interaction are talked about in a self-evidentiary manner. They are not always defined and if they are, this tends to be in a narrow way. Participation for example is usually defined in numerical terms, and can refer both to the total number of members of the online discussion group, as well as the number who actually contribute (Henri, 1992). Interactivity is often defined somewhat loosely and seems to be interchangeable with other terms such as communication, participation and engagement. Anderson (2003) argues that interaction involves a two way contact between people or with content and that in formal educational contexts, is used intentionally to achieve learning objectives or outcomes. Anderson suggests that there can be different types of interaction, including student to student, student to teacher and student to content, but that "deep and meaningful formal learning is supported as long as one of the three forms of interaction ... is at a high level."

Both participation and interaction typically are evidenced by an analysis of the transcript of the online discussion. To be counted as a participant one needs to leave a physical record, thus those who don't, such as those who choose to observe for example, are not counted. Often these non-participants are considered lurkers, which Carr and Chambers (2006: 146) acknowledge are a part of online culture, though adding that "having a high proportion of lurkers may undermine the development of the community - there needs to be sufficient public interaction to act as a stimulus for discussion, debate or learning". Anderson (2003) expresses a similar view about the importance of active interaction in online discussion when he comments that "high levels of interaction generally require actors to be personally active and engaged in the interaction".

Participation is also often assumed to occur when the technological means to do so has been enabled. Maxwell et al. (2010) for example point out that 380 graduates could have participated in their EdASP network, but only 125 chose to do so. Often as well, researchers seem to assume that participation will be constant and are somewhat apologetic when it doesn't turn out that way. Schuck (2003) for example comments that a number of beginning teachers stopped contributing to discussion, a number participated infrequently and only 5 of the 18 consistently choose to participate over the year. Broader discussions about why participants may want to participate are often not explored.

Measuring participation, whether it specifically involve participation rates, or patterns in participation, perhaps by gender, topic or over time has been a matter of counting. Measuring interactivity has been more complex as what can be counted as interactivity is more open to interpretation and different classification schemes measure it in different ways. Indeed as online discussion technologies have enabled interaction to occur between multiple participants, measuring interactivity has become more difficult, especially when it involves many participants over a long period of time. Yet interactivity is perceived as important to the success of online discussion, based on the belief that without it, online discussion "would comprise a series of statements linked only by the theme or subject under discussion - we would be faced with a collection of monologues and one-way statements" (Henri, 1992: 128). Yet despite the importance placed on being able to interact, once the technological means to enable interaction has been realised, possible efforts to ensure participants know how to interact are forgotten. Thus, both participation and interactivity are essentially seen as technical issues of connectivity, rather than pedagogical issues, situated within particular contexts. 


\section{Content analysis of online discussion}

Content analysis is the dominant method used to analyse online discussion. In broad terms, content analysis usually takes as its first point of reference, the transcript, or the visible record of the content that was discussed. This transcript is read and analysed and particular codes using a particular classification scheme or taxonomy are assigned to aspects of the text. Typically this is at the level of a sentence or paragraph. Various models have been developed including Henri's model (1992) used in other studies such as those by Hara, Bonk and Angeli (2000) and McKenzie and Murphy (2000), as well as models by Gunawardena, Lowe and Anderson (1997), and Garrison, Anderson and Archer (1999). Content analysis of online discussion can be "difficult, frustrating and time-consuming" (Rourke et al, 2001). There are a number of issues with content analysis, including its reliance often on surface, text-based content, or visible content and as such the context, under which transcription is produced is not included (Enriquez, 2009; Rourke et al. 2001). As well there are considerable issues regarding rigour, as well as issues of reliability, validity and replicability (Rourke, Anderson, Garrison \& Archer, 2001).

While the use of online discussion has been the subject of much research over a considerable period of time, there are still many questions that need answering. This is largely because much of the research has been mainly techno-centric in nature, with particular affordances such as the asynchronous nature of online discussion often identified as the means to solve perceived problems. In relation to teachers, asynchronous technologies have often been seen as overcoming issues in teacher professional learning, such as teacher isolation and lack of teacher reflection. Whether teachers received training in how to use these online discussions often was not reported, contributing further to the view that using them is simple and straightforward. Some of the more complex questions of how these technologies can be used in educational contexts have not been asked.

As well the research literature is underpinned by many assumptions, particularly around perceived benefits of their use, assumptions that are rarely evaluated. Some assumptions also relate to the users of these online technologies, particularly those deemed 'digital natives'. This paper is particularly interested in whether beginning teachers have the knowledge and skills to participate and interact in online discussion. Data is drawn from simulated online discussion which formed part of a larger support program for beginning teachers from P-12 schools across the state of Victoria.

\section{This study}

Beginning in 2010, and now in its second year of a three year program, the Supporting New Teachers Practice (SNTP) program is a Victorian Department of Education and Early Childhood Development (DEECD) initiative, which aims to provide further support to beginning teachers as they face the challenges of being new to the profession. Beginning teachers volunteer to participate, and are provided with teaching release to enable ease of participation. Costing over $\$ 1$ million, the program will involve around 600 beginning teachers, from across the state. This paper reports on one cohort of beginning teachers, 64 beginning teachers, 52 females and 12 males from primary, secondary and specialist schools from across the state. 
The SNTP program uses a blended design. It begins with a two day face to face program, which aims to give beginning teachers opportunities to share their first year experiences as well as some challenges to their practice. On the second day of this program, considerable time is spent helping beginning teachers form smaller groups or communities, around a common interest or shared issue in practice (Wenger, 1998). Later, each of these communities is assigned an online coach, an experienced teacher whose role is to support the community. A large part of this day is also spent in preparing the beginning teacher communities to be able to operate in the online component of the program. The program technologies are discussed, and each beginning teacher is given a resource folder containing hint sheets on how to use these technologies, as well as a protocol to assist them when discussing online.

In their communities they discuss how to appropriately use these technologies, given that they are in a public space, and they participate in a simulated online discussion. The online component follows on from the face to face program and then continues for much of the rest of the school year. This component essentially has two functions, to provide them with further knowledge about issues affecting their practice and to provide a space for them as a community to share experiences and develop shared practice (Wenger, 1998). Several technologies within Blackboard are used to achieve these aims, as outlined in Appendix 1.

\section{Data collection and analysis}

Data for this paper is drawn from the written record of the simulated online discussion activity, which formed part of the face to face program. This simulation aimed to focus beginning teachers on behaviours which could assist their discussion when later online. These behaviours included: using open statements, soliciting replies by using questions, agreeing and disagreeing to a post in an appropriate way, and asking for clarity when unsure of the content or a view in a post. Details are included in Appendix 2. Beginning teachers operated within communities, which they had selfformed earlier that day, based on a common interest. In the main, these community groups were made up of 4-6 beginning teachers who had not met previously, who taught in different schools and across sectors. The simulation came at the end of a session around introducing beginning teachers to the program technologies, and discussing online.

The beginning teachers were asked to read four scenarios (see Table 1 below) provided in large text in hard copy format. They were then asked to choose one of these scenarios to respond to as a community group by simulating online discussion. Each of these scenarios centred on a particular issue or issues that beginning teachers were likely to experience, and ended with a prompt, to focus and stimulate discussion. Beginning teachers were given Post-it notes with which to record posts to this simulation and given a thirty minute timeframe.

Data from 19 simulated discussions was then collected and later transcribed. Henri's (1992) model of content analysis was broadly used to frame an analysis of participation and interaction by beginning teachers. This model has been used by Gunawardena, Lowe and Anderson (1997) and McKenzie and Murphy (2000) in Australia, and Khine, Yeap and Lok (2003) in Singapore. 
Table 1: Scenarios to stimulate discussion

\begin{tabular}{|c|c|c|}
\hline $\begin{array}{l}\text { Scenario } \\
\text { focus }\end{array}$ & Scenario & Explanation of scenario \\
\hline $\begin{array}{l}\text { Scenario 1 } \\
\text { focuses on } \\
\text { identifying } \\
\text { issues to } \\
\text { practice. }\end{array}$ & $\begin{array}{l}\text { A topic on the Discussion Board has } \\
\text { involved 'engaging students' and Rebecca } \\
\text { has posted this posting: } \\
\text { Rebecca: My Year 9's played up again today. } \\
\text { I'm just not sure what to do! Many of my } \\
\text { students don't like school and I feel like I'm } \\
\text { hitting my head against a brick wall. Uni didn't } \\
\text { prepare me for this! Most don't read much and } \\
\text { can't really well. So much for the Education } \\
\text { Revolution! I still can't get them to bring their } \\
\text { book to class and without it, doing the } \\
\text { assignment is difficult. Today I sent four of } \\
\text { them who hadn't brought their books - yet again } \\
\text { - to the coordinator. I'm dreading next week. I } \\
\text { know at least half of them won't have done the } \\
\text { comprehension questions I told them to do. } \\
\text { Rebecca is having a range of issues with her } \\
\text { Year 9's. What would you say to get her to } \\
\text { isolate these issues? }\end{array}$ & $\begin{array}{l}\text { Rebecca a beginning teacher is facing } \\
\text { a number of issues. She does not } \\
\text { know what to do about the students } \\
\text { who come to class not prepared with } \\
\text { the textbook, and who have reading } \\
\text { problems and don't like reading. She } \\
\text { has tried one strategy, of sending } \\
\text { students who come unprepared to } \\
\text { coordinators, but doesn't know what } \\
\text { to do next time this happens as she } \\
\text { predicts it will. She feels that her } \\
\text { university course has let her down by } \\
\text { not equipping her with strategies to } \\
\text { deal with these situations. The prompt } \\
\text { at the end of this scenario asks } \\
\text { beginning teachers to help Rebecca to } \\
\text { isolate the issues she is facing. The } \\
\text { intent is that beginning teachers will } \\
\text { practice being able to focus discussion } \\
\text { and therefore encourage discussion to } \\
\text { be more purposeful and meaningful. }\end{array}$ \\
\hline $\begin{array}{l}\text { Scenario } 2 \\
\text { focuses on } \\
\text { beginning } \\
\text { teacher and } \\
\text { mentor } \\
\text { relation- } \\
\text { ships. }\end{array}$ & $\begin{array}{l}\text { Discussion on the Discussion Board has } \\
\text { broadly been about mentors. Jasmine posts } \\
\text { this posting in response to a previous one } \\
\text { by Kathy. } \\
\text { Jasmine: I'm jealous Kathy! Yours sounds like a } \\
\text { saint! Mine is a real dragon! I'm really } \\
\text { struggling. She is so much older than me and } \\
\text { has so much experience that she makes me feel } \\
\text { like an idiot! I want to talk to her about the } \\
\text { trouble I'm having with two of my boys. She's } \\
\text { taught them. But I don't know how to raise it } \\
\text { with her. } \\
\text { As Kathy, a fellow beginning teacher who } \\
\text { apparently has a 'saint' for a mentor, how } \\
\text { will you acknowledge Jasmine's concerns? } \\
\text { You could try some reflective listening? } \\
\text { What would you say to Jasmine without } \\
\text { 'telling her what you would do'? }\end{array}$ & $\begin{array}{l}\text { Jasmine a beginning teacher is feeling } \\
\text { reluctant about asking her mentor to } \\
\text { assist her as she feels intimidated by } \\
\text { her mentor who is older and more } \\
\text { experienced. The prompt at the end of } \\
\text { the scenario asks beginning teachers } \\
\text { to acknowledge Jasmine's concerns } \\
\text { while avoiding telling her what to do. } \\
\text { The intent is that beginning teacher s } \\
\text { will gain practice in acknowledging } \\
\text { issues that matter to others while at } \\
\text { the same time, ensuring ownerships } \\
\text { of the issue is maintained rather than } \\
\text { a solution being offered by another. }\end{array}$ \\
\hline $\begin{array}{l}\text { Scenario } 3 \\
\text { focuses on } \\
\text { relating to } \\
\text { parents and } \\
\text { learners. }\end{array}$ & $\begin{array}{l}\text { Justin: Help! I've just had a parent of one of my } \\
\text { Year } 5 \text { girls here to see me - virtually in tears - } \\
\text { asking me what I can do to help. Her daughter is } \\
\text { really shy -you know, one of those who barely } \\
\text { says boo-and the other children ignore for most } \\
\text { of the time. Anyway she is going home crying } \\
\text { and says she doesn't want to go to school. } \\
\text { What questions can you ask Justin, to } \\
\text { encourage him to elaborate more on the } \\
\text { student and to explore the situation more } \\
\text { from a range of perspectives? }\end{array}$ & $\begin{array}{l}\text { A parent asks Justin, a beginning } \\
\text { teacher for help with her daughter } \\
\text { who is feeling so isolated from the } \\
\text { other children that she doesn't want to } \\
\text { go to school. The prompt invites } \\
\text { beginning teachers to ask Justin } \\
\text { questions so as to explore the issue } \\
\text { from a range of perspectives. In this } \\
\text { way, it is intended that beginning } \\
\text { teachers will practice opening up } \\
\text { discussion other than perhaps looking } \\
\text { at it simplistically. }\end{array}$ \\
\hline
\end{tabular}




\begin{tabular}{|l|l|l|}
\hline $\begin{array}{l}\text { Scenario } 4 \\
\text { relates to } \\
\text { classroom } \\
\text { manage- } \\
\text { ment } \\
\text { strategies. }\end{array}$ & $\begin{array}{l}\text { A discussion has been going on for some } \\
\text { time about relating to students and } \\
\text { classroom management issues. You read } \\
\text { this posting from Sammi. }\end{array}$ & $\begin{array}{l}\text { Sammi a beginning teacher explains } \\
\text { her classroom management strategies } \\
\text { that she learned from her mentor } \\
\text { including publically listing } \\
\text { they don't, I tick their name off on a chart that I } \\
\text { have at the front of the room that all the kids can } \\
\text { see. My mentor used this last year. If they } \\
\text { interrupt again or call out - I can't stand that - } \\
\text { I put another cross against their name - and } \\
\text { they know what will happen if they do it for a } \\
\text { third time! } \\
\text { with this strategy and to turn the } \\
\text { discussion to other more positive } \\
\text { strategies. The intent is that beginning } \\
\text { teachers will practice disagreeing and } \\
\text { reframing a discussion. }\end{array}$ \\
& $\begin{array}{l}\text { How will you disagree with Sammi's } \\
\text { strategy and manoeuvre the discussion to a a } \\
\text { more positive turn? }\end{array}$ & \\
\hline
\end{tabular}

Henri's (1992) model of analysis is based on categorising 'message units' into five dimensions of learning, participation, interaction, social, and cognitive and metacognitive. The two dimensions of participation and interaction are most relevant to this study. Henri defines participation as direct involvement in the discussion, therefore the number of posts by an individual or a group are counted. To measure interaction, the connection between posts are then coded and counted. Interaction, defined by Henri is a three-step process: Step 1, information is communicated, Step 2, a response is made to this information, and then Step 3, a second answer relating back to the first is made. She then further categorises interactions as explicit, implicit or independent. An explicit interaction is where one or more ideas refer explicitly to one or more messages. An implicit interaction is where one or more messages or ideas do not specifically mention a connection. Independent interactions are statements relating to discussion but which do not respond or comment on it. Explicit and implicit interactions are further coded as a commentary, that is a comment on someone else's post or a response, that is a response to a question posed. Henri's model, while considered highly influential (McKenzie \& Murphy, 2000; Marra, Moore \& Klimczak, 2004; Enriquez, 2009) also has considerable criticism. In the main, this often relates to her definition of interaction, which focuses on the connections between posts, rather than perhaps to the discussion as a whole (Gunawardena, Lowe \& Anderson 1997; Marra et al. 2004; Enriquez, 2009).

In order to gauge participation by beginning teachers in the simulations, the number of posts, deemed a 'message unit', was counted. Then, to gauge interactivity, each message unit was classified as either an explicit, implicit or an independent statement. Examples of how these message units were classified are shown in Table 2. Participation rates and interactions (direct, indirect and independent) are shown in Table 3.

\section{Limitations of this study}

This paper has several limitations. Firstly, this study is small scale, involving some 64 beginning teacher participants in a 30 minute simulation. As a result this study can be best seen as suggestive. Secondly, the beginning teachers' capacity to participate in this simulation may have been influenced by a number of factors. This includes the fact that the majority did not know one another, and came from different schools and 
different school types and therefore needed to establish rapport. Lack of teaching experience and possible ability to engage in professional discussions at this early stage of their career may have also contributed. As well, the beginning teachers were asked to discuss hypothetical situations, and while designed around issues that organisers felt would be familiar, may not have been. Thirdly, there are also limitations with the data collection and analysis methods. Data for this study involved collecting written simulations with attached Post-it notes, and while efforts were made to preserve the artefacts, the researcher did need to use her judgment to reaffix some of these notes. As well, the researcher was not present at all locations and so cannot verify that the same instructions were given to each cohort of beginning teachers by way of introducing the simulation activity. Thus there are some issues regarding the reliability of the data. There are also data analysis issues as a result of choosing to use Henri's framework as mentioned previously.

Table 2: Classification of interactivity

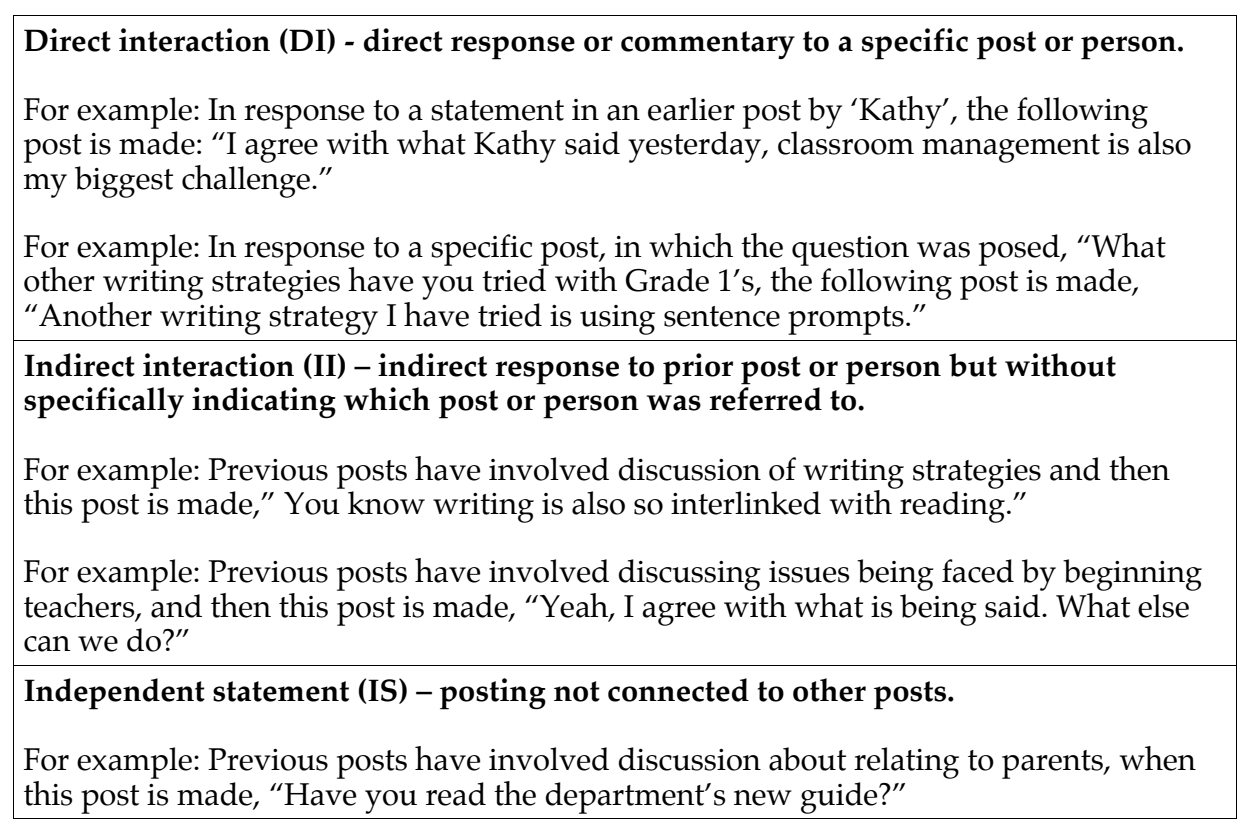

\section{Results}

\section{Participation}

As shown in Table 3, six groups of beginning teachers discussed the first scenario relating to reluctant readers, three groups the second scenario relating to feeling inadequate with a mentor, seven in relation to the third scenario on relating to parents and four on the last scenario relating to classroom management. There was some 147 'message units' or posts made to 19 simulated networks. Each of these simulations received around 7 'message units'. This does indicate that beginning teachers participated in the simulation, although the variation in the number of posts suggests that some beginning teachers participated more than others. The third scenario was somewhat more popular than others. 
Table 3: Participation rates and interaction

\begin{tabular}{|c|c|c|c|c|c|}
\hline $\begin{array}{l}\text { Number of } \\
\text { scenario }\end{array}$ & $\begin{array}{l}\text { Number of } \\
\text { groups }\end{array}$ & $\begin{array}{l}\text { Number } \\
\text { of posts }\end{array}$ & $\begin{array}{l}\text { Independent } \\
\text { statements (IS) }\end{array}$ & $\begin{array}{l}\text { Direct inter- } \\
\text { actions (DI) }\end{array}$ & $\begin{array}{l}\text { Indirect inter- } \\
\text { actions (II) }\end{array}$ \\
\hline \multirow[t]{6}{*}{ Scenario 1} & Group 1 & 7 & 7 & 0 & 0 \\
\hline & Group 2 & 7 & 6 & 1 & 0 \\
\hline & Group 3 & 7 & 6 & 1 & 0 \\
\hline & Group 4 & 10 & 6 & 2 & 2 \\
\hline & Group 5 & 5 & 3 & 0 & 2 \\
\hline & Group 6 & 8 & 6 & 2 & 0 \\
\hline Sub-total & 6 & 44 & 34 & 6 & 4 \\
\hline \multirow[t]{2}{*}{ Scenario 2} & Group 1 & 9 & 2 & 5 & 2 \\
\hline & Group 2 & 12 & 3 & 5 & 4 \\
\hline Sub-total & 2 & 21 & 5 & 10 & 6 \\
\hline \multirow[t]{7}{*}{ Scenario 3} & Group 1 & 9 & 7 & 1 & 1 \\
\hline & Group 2 & 7 & 3 & 4 & 0 \\
\hline & Group 3 & 8 & 4 & 2 & 2 \\
\hline & Group 4 & 9 & 0 & 2 & 7 \\
\hline & Group 5 & 6 & 3 & 2 & 1 \\
\hline & Group 6 & 7 & 3 & 2 & 2 \\
\hline & Group 7 & 4 & 3 & 1 & 0 \\
\hline Sub-total & 7 & 50 & 23 & 14 & 13 \\
\hline \multirow[t]{4}{*}{ Scenario 4} & Group 1 & 7 & 5 & 2 & 0 \\
\hline & Group 2 & 7 & 1 & 4 & 2 \\
\hline & Group 3 & 7 & 2 & 4 & 1 \\
\hline & Group 4 & 11 & 2 & 6 & 3 \\
\hline Sub-total & 4 & 32 & 10 & 16 & 6 \\
\hline Total & 19 & 147 & 72 & 46 & 29 \\
\hline
\end{tabular}

Note: As data was analysed by interactivity with other posts, the first post in each simulation did not figure in this analysis.

\section{Interactivity}

The beginning teachers, operating within 19 separate communities, posted some 147 posts to the simulation. Of these around half, some 72 posts were rated as Independent statements (IS) that is they did not connect with other posts. Some 75 were rated as interactive, with 46 considered as Direct interaction (DI), that is direct response or commentary to a specific post or person and 29 rated as Indirect interactions (II), an indirect response to a prior post or person but without specifically indicating which post or person was referred to. A closer analysis by scenario reveals some differences. Scenario 1 for example received some 44 posts by 6 communities, however in comparison to other scenarios, received more Independent statements and less interaction. Scenario 2 while receiving some 21 posts by 2 communities had higher levels of interaction, and less number of Independent statements. Perhaps then the scenario, itself may have been a contributing factor.

In order to present a richer picture of the simulated online discussion, I present a detailed analysis of two of them. The first example is more typical of the interactions, while the second is not.

\section{Example simulation 1}

In this simulation a small group of beginning teachers is responding to the first scenario, involving Rebecca, a beginning teacher who is facing a number of issues. The prompt at the end of this scenario asks beginning teachers to help Rebecca to isolate 
the issues she is facing. The intent is that beginning teachers will practise being able to focus discussion and therefore encourage discussion to be more purposeful and meaningful.

Some seven posts were made to this simulation; this is the average number of posts made to all the twenty simulations. All posts in this example are Independent statements with none directly responding to the prompt which invited them to help Rebecca identify issues she is facing. Instead, beginning teachers post a view, which in essence tries to solve what they perceive as the issue that in effect then shifts control of the perceived issue to them rather than Rebecca. One beginning teacher assumes that the issue is about engagement and that more-so Rebecca has failed in this regard, resulting in the post, "Rebecca, how do you think you could engage these students? What could you try that is different that might draw them in?" Another assumes that the issue is about her expectations, posting this, "Hey Bec, it can be tough sometimes to balance our expectations and their actions. Remember you can only do so much but try." Another suggests that the issue is about reading and recommends another strategy, "Have you thought of either reading the text to the students or putting the text onto a CD so that the children can listen to it?" By giving solutions, sometimes couched as questions, interaction is closed rather than opened.

These discussant behaviours, whereby individual beginning teachers make a post and do not attempt to make links with other ideas being posted, or are not in direct response to the prompt, suggest they have a narrow perception of what online discussion involves. This seems to be one centred on providing 'an answer' to what they see as the problem.

\section{Example simulation 2}

The second example is atypical of the patterns that tended to emerge from these simulated discussions, in that there was a higher level of interactivity. The beginning teachers respond to the fourth scenario, in which Sammi a beginning teacher explains her classroom management strategies. The prompt invites them to challenge her strategy and to turn the discussion to other more positive strategies. The intent is that beginning teachers will practise disagreeing and reframing a discussion.

There were eleven posts made to this simulation, which is higher in number than others, with six being classified as Direct interactions and three as Indirect interactions. The three Indirect interactions tend to use statements, often drawing on examples from their own practice, such as in this post, "In my grade we focus on the positive. So rather than pointing out students that are not listening as a group, reward those that are." Four of the six Direct interactions use a mix of statements and questions, as well as personal experience. This mix of questions and statements, serves to invite another post and therefore keep the discussion flowing as illustrated in this extract:

Post: I have tried this strategy myself but have found it is always the same names on the board. Something I have tried is putting the names of people that are listening on board which has worked well. Is this something you think might work in your class?

Post: Yes, I could give that a try, but what happens to those who aren't listening? How long do you let them go without reprimand? 
Post: I would reprimand straight away through the use of a book where you use a warning system. I would rather do this than use names on the board as it can be demeaning to the students. What other strategies are being used within your school? Is there a PD coming up you can attend?

These discussion behaviours in the preceding simulation, whereby beginning teachers seem to be aware of the need to invite a response and to respond to another response, indicates that they have more understanding of the pedagogies that can foster higher level of interaction.

\section{Discussion and conclusion}

The use of online discussion within teacher networks has been proposed as a way of providing beginning teachers with further support when new to the profession. Often these networks, are proposed as the asynchronous affordance is identified as a means of overcoming barriers to teacher professional learning such as isolation and reflection on practice. This research however often makes a lot of assumptions about online discussion that are underpinned by techno-centric views. A lot of assumptions have been made about beginning teacher level of skill to use technologies because of their age and assumed comfort levels with technologies.

This paper has reported on the first stage of a large 3 year DEECD initiative involving some 64 beginning teachers from across the state of Victoria. The program broadly aims to support these beginning teachers as they face challenges of being new to the profession, through a blended learning environment. The choice of a blended environment was a deliberate one: To make the best use of face to face learning by giving participants opportunities to get to know one another and the best of online learning, to provide further opportunities to explore issues through online discussion. The program employed the use of communities of practice, in order to encourage shared ownership, and online coaches whose main role was to support online discussion.

In this small scale study 64 beginning teacher participated in a simulated online discussion. They had been introduced prior to the program technologies and the use of a protocol to guide discussion and had explored issues around discussing online. This study is based on the analysis of a simulated online discussion designed around a scenario, and using a prompt to frame discussion. The findings suggest that these beginning teachers do not necessarily have the knowledge to interact effectively in an online professional learning environment. Overall the level of interaction, either direct or indirect was relatively low in each of the simulated online discussions or networks. In the main, instead of interactions, beginning teachers tended to post Independent statements unconnected with other ideas in other posts. Typically they tended to use statements and closed questions to give advice and solutions and made little effort to directly interact with other posts. Rather than interacting, beginning teachers tended to instruct, and 'tell what to do'. Beginning teachers ignored prompts at end of scenarios instead posting their own view on what they perceived were the issues at hand. Indeed this appears to be their prime motivation, as evidenced by patterns in their posts.

This study suggests that beginning teacher networks may not achieve their intention of providing a supportive environment. Furthermore, it suggests that beginning teachers have a narrow view of online discussion and lack wider pedagogical knowledge with 
which to interact online. While that is not necessary to a successful discussion, it is needed to sustain it. Future beginning teacher networks could consider paying attention to developing and practising online discussion skills. Attention could also be given in pre-service education to the importance of having explicit skills to be able to discuss online. Greater consideration could also be given to these skills through professional learning programs.

\section{References}

Anderson, T. (2003). Getting the mix right again: An updated and theoretical rationale for interaction. The International Review of Research in Open and Distance Learning, 4(2). http: / / www.irrodl.org/index.php/irrodl/article/view/149/230

Bennett, S., Maton, K. \& Kervin, L. (2008). The 'digital natives' debate: A critical review of the evidence. British Journal of Educational Technology, 39(5), 775-786. http: / / dx.doi.org/10.1111/j.1467-8535.2007.00793.x

Carr, N. \& Chambers, D. P. (2006). Teacher professional learning in an online community: The experiences of the National Quality Schooling Framework Pilot Project. Technology, Pedagogy and Education, 15(2), 143-157. http:/ / dx.doi.org/10.1080/14759390600769094

Darling-Hammond, L. (1990). Teacher supply, demand and quality. Washington, DC: National Board for Professional Standards.

Department of Education and Early Childhood Development (DEECD). Teacher Support Mentor Program website. [viewed 1 Aug 2011].

http: / / www.education.vic.gov.au/proflearning/teacher/mentorprog.htm

De Wert, M. H., Babinski, L. M. \& Jones, B. D. (2003). Safe passages. Providing online support to beginning teachers. Journal of Teacher Education, 54(4), 311-320. http: / / dx.doi.org/ 10.1177/0022487103255008

Enriquez, J. G. (2009). Discontent with content analysis of online transcripts. Association for Learning Technology Journal, 17(2), 101-113. http:/ / dx.doi.org/10.1080/09687760903033066

Gao, P., Wong, A. F. L., Choy, D. \& Wu, J. (2010). Developing leadership potential for technology integration: Perspectives of three beginning teachers. Australasian Journal of Educational Technology, 26(5), 643-658. http:/ / www.ascilite.org.au/ajet/ajet26/gao.html

Garrison, D. R., Anderson, T. \& Archer, W. (1999). Critical inquiry in a text-based environment: Computer conferencing in higher education. The Internet and Higher Education, 2(2-3), 87-105. http: / / dx.doi.org/ 10.1016/S1096-7516(00)00016-6

Gunawardena, C. N., Lowe, C. A. \& Anderson, T. (1997). Analysis of a global online debate and the development of an interactive analysis model for examination social construction of knowledge in computer conferencing. Journal of Educational Computing Research, 17(4), 397431. http:/ / hdl.handle.net/2149/772

Hara, N., Bonk, C. \& Angeli, C. (2000). Content analysis of online discussion in an applied educational psychology course. Instructional Science, 28(2), 115-152. http: / / dx.doi.org/ 10.1023/ A:1003764722829

Henri, F. (1992). Computer conferencing and content analysis. In A. R. Kaye (Ed), Collaborative learning through computer conferencing: The Najaden Papers, 117-136. Berlin: Springer-Verlag. 
Herrington, A., Herrington, J., Kervin, L. \& Ferry, B. (2006). The design of an online community of practice for beginning teachers. Contemporary Issues in Technology and Teacher Education, 6(1), 120-132. http: / / www.citejournal.org/vol6/iss1/general/article1.cfm

Kennedy, G. E., Judd, T. S., Churchward, A., Gray, K. \& Krause, K. (2008). First year students' experiences with technology: Are they really digital natives? Australasian Journal of Educational Technology, 24(1), 108-122. http:// www.ascilite.org.au/ajet/ajet24/kennedy.html

Khine, M. S., Yeap, L. L. \& Lok, A. T. C. (2003). The quality of message ideas, thinking and interaction in an asynchronous CMC environment. Educational Media International, 40(1-2), 115-125. http: / / dx.doi.org/10.1080/0952398032000092161

McKenzie, W. \& Murphy, D. (2000). 'I hope this goes somewhere": Evaluation of an online discussion group. Australian Journal of Educational Technology, 16(3), 239-257. http: / / www.ascilite.org.au/ajet/ajet16/mckenzie.html

Marra, R. M., Moore, J. L. \& Klimczak, A. K. (2004). Content analysis of online discussion forums: A comparative analysis of protocols. Educational Technology Research and Development, 52(2), 23-40. [verified 17 Nov 2011] http:/ / institute.nsta.org/scipack_research/content_ analysis_online_discussion_forums_etrd.pdf

Maxwell, T. W., Harrington, I. \& Smith, H. J. (2010). Supporting primary and secondary beginning teachers online: Key findings of the education alumni support project. Australian Journal of Teacher Education, 35(1), 42-58.

http: / / ro.ecu.edu.au / cgi/ viewcontent.cgi?article=1328\&context=ajte

Moore, J. A. \& Chae, B. (2007). Beginning teachers' use of online resources and communities. Technology, Pedagogy and Education, 16(2), 215-224. http: / / dx.doi.org/10.1080/14759390701406844

Prensky, M. (2001). Digital natives, digital immigrants. On the Horizon, 9(5). Accessed on 3 June, 2011. http: / / www.marcprensky.com/ writing/Prensky\%20$\% 20$ Digital $\% 20$ Natives, $\% 20$ Digital\%20Immigrants\%20-\%20Part1.pdf

Romano, M. E. (2008). Online discussion as a potential professional development tool for firstyear teachers. Technology, Pedagogy and Education, 17(1), 53-65. http: / / dx.doi.org/10.1080/14759390701847591

Rourke, L., Anderson, T., Garrison, D. R. \& Archer, W. (2001). Methodological issues in the content analysis of computer conference transcripts. International Journal of Artificial Intelligence in Education, 12(1), 8-22. http:/ / iaied.org/pub/951/

Schuck, S. (2003). Getting help from the outside: Developing a support network for beginning teachers. Journal of Educational Enquiry, 4(1), 49-67.

http: / / www.ojs.unisa.edu.au/index.php/EDEQ/article/viewFile/531 / 401

Wenger, E. (1998). Communities of practice: Learning, meaning and identity. Cambridge: Cambridge University Press.

Zhao, Y. \& Rop, S. (2001). A critical review of the literature on electronic networks as reflective discourse communities for inservice teachers. Education and Information Technologies, 6(2), 8194. http: / / dx.doi.org/10.1023/ A:1012363715212 


\section{Appendix 1: Technologies used in Supporting New Teachers' Practice program}

\begin{tabular}{|l|l|}
\hline \multicolumn{1}{|c|}{$\begin{array}{c}\text { Technology } \\
\text { application }\end{array}$} & \multicolumn{1}{c|}{ Purpose and expectations } \\
\hline $\begin{array}{l}\text { Chat } \\
\text { (synchronous) }\end{array}$ & $\begin{array}{l}\text { Each community participated in three chat sessions, each for an hour on a } \\
\text { particular theme as decided by the program team, the individual online } \\
\text { coach or the community themselves. For example, one common topic was } \\
\text { around exploring a challenge to practice. }\end{array}$ \\
\hline $\begin{array}{l}\text { Discussion board } \\
\text { (asynchronous) }\end{array}$ & $\begin{array}{l}\text { Each community was able to use a discussion board, as they saws fit, to } \\
\text { explore issues that matter to them, and to reflect on their practice. The } \\
\text { online coach acted as a moderator of these online community spaces. }\end{array}$ \\
\hline $\begin{array}{l}\text { Elluminate } \\
\text { (synchronous), } \\
\text { text and audio and } \\
\text { multimedia }\end{array}$ & $\begin{array}{l}\text { Three Elluminate sessions of 1 hour each were presented over the program, } \\
\text { with all participants expected to participate. These sessions were presented } \\
\text { by a member of the project team and moderated by another. Audio was } \\
\text { managed in order to facilitate interaction, so only some participants (usually } \\
\text { two from each community) had a speaking role in these sessions. }\end{array}$ \\
\hline Ning & $\begin{array}{l}\text { A Ning [http://www.ning.com/], serving as a social networking site was } \\
\text { linked to the Blackboard site and provided a space where participants could } \\
\text { informally communicate with others in the program, at a time that suited. }\end{array}$ \\
\hline
\end{tabular}

\section{Appendix 2: Online discussion protocol}

In order to discuss effectively and productively we need to:

- solicit responses (ask questions, seek feedback, seek agreement, ask for other supporting evidence)

- build discussion (look for agreement, clarify, refine)

What to do:

- Solicit discussion by posing questions, and asking for feedback

- Explicitly agree, and disagree with ideas

- Don't make your postings too long. Try to break into threads.

- Use first person "I"

- Focus on solving problems and having productive discussion

- Use a mix of conversational type language and more considered language

- Model good answers. "I agree with what you are saying about classroom management being the biggest hurdle. I found this out very quickly when I began teaching. However, I have successfully tried some strategies..." Rather than, "I agree."

- Use questions to prompt discussion rather than give answers

- Seek clarification of ideas being presented

- Ask for evidence to support a position

- Ask to elaborate

- Look for similarities in ideas being discussed

- Identify areas of agreement and areas of disagreement when responding to another post

- Clarify ideas

- Remember that there is no one answer - there are always many ways to look at an issue

- Read what others have to say - and reserve your judgment 
- Look for ways that a view connects with your ideas

- Be open minded rather than closed

- Be conscious of your intent - if it is to discuss - to explore ideas and views - then post - if it is to just 'hear your own voice' then perhaps think twice

- Ask for other perspectives

- Poll an idea

- Pose engaging questions

- Challenge positions

- Identify areas of conflict

- Think about how to build a response

- Debate ideas

- Acknowledge other's views

Author: Kathy Jordan, Lecturer in Literacy and Program Co-ordinator Grad Dip (Secondary), Design and Social Context Portfolio, School of Education,

RMIT University, Bundoora West Campus, Bundoora VIC 3083 Australia

Email: kathy.jordan@rmit.edu.au

Please cite as: Jordan, K. (2011). Do beginning teachers know how to participate and interact in online discussion? Outcomes from a Victorian case study. Australasian Journal of Educational Technology, 27(7), 1247-1262.

http: / / www.ascilite.org.au/ajet/ajet27/jordan.html 